\title{
REGULATORY ISSUES AND ASSUMPTIONS ASSOCIATED WITH BARRIERS IN THE VADOSE ZONE SURROUNDING BURIED WASTE
}

\author{
Barry Siskind \\ John Heiser \\ (Principal Investigator)
}

February 1993

ENVIRONMENTAL AND WASTE TECHNOLOLYY CENTER

DEPARTMENT OF NUCLEAR ENERGY

BROOKHAVEN NATIONAL LABORATORY

ASSOCIATED UNIVERSITIES, INC.

UPTON, NEW YORK 11973

UNITED STATES DEPARTMENT OF ENERGY

CONTRACT NO. DE-ACO2-76CH0OO16

TTP NO.: CH331001 


\section{TABLE OF CONTENTS}

Page

LIST OF FIGURES and LIST OF TABLES $\ldots \ldots \ldots \ldots \ldots \ldots \ldots \ldots$

EXECUTIVE SUMMARY $\ldots \ldots \ldots \ldots \ldots \ldots \ldots \ldots \ldots \ldots \ldots \ldots \ldots \ldots \ldots$

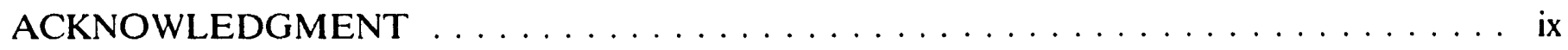

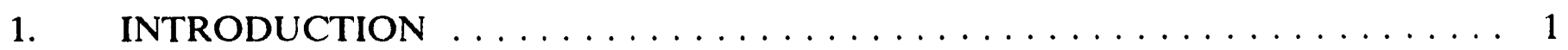

2. USE OF SUBSURFACE BARRIERS FOR CONTROLLING

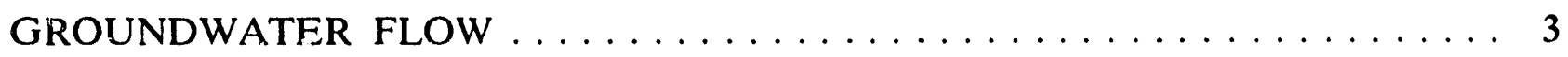

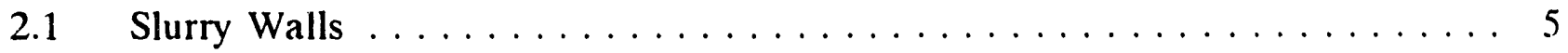

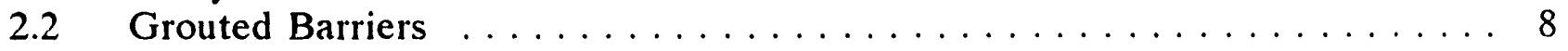

2.3 Conclusions on EPA's Acceptance of

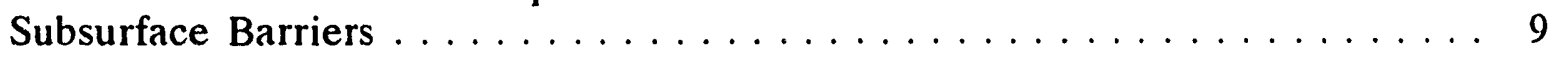

3. HEALTH, SAFETY AND ENVIRONMENTAL ISSUES

RELATED TO SUBSURFACE BARRIER TECHNOLOGY $\ldots \ldots \ldots \ldots \ldots, 10$

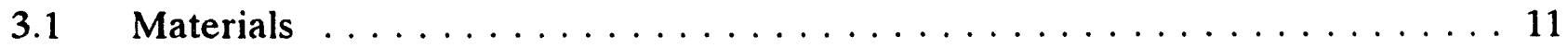

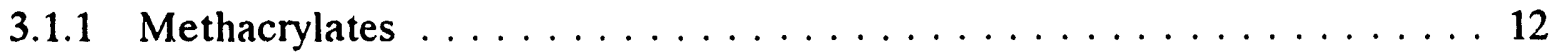

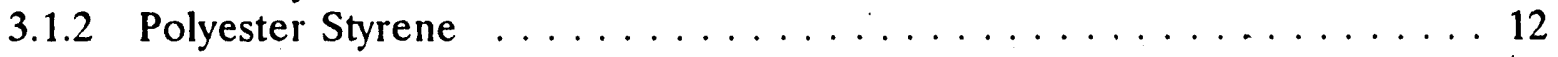

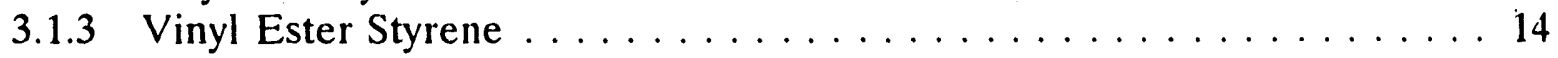

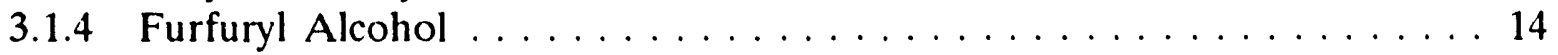

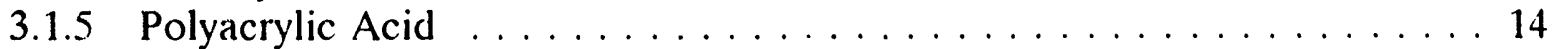

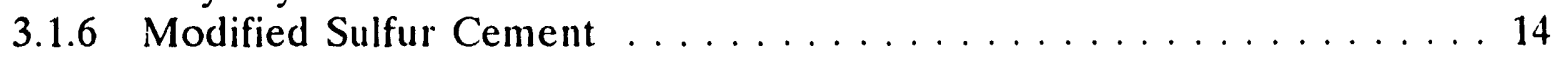

3.2 OSHA Standards - Air Contaminants $\ldots \ldots \ldots \ldots \ldots \ldots \ldots \ldots \ldots \ldots \ldots \ldots \ldots \ldots$

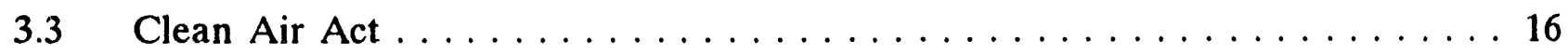

3.3.1 Standards of Performance for

New Stationary Sources . . . . . . . . . . . . . . 16

3.3.2 National Emission Standards for
Hazardous Air Pollutants $\ldots \ldots \ldots \ldots \ldots \ldots \ldots \ldots \ldots \ldots$

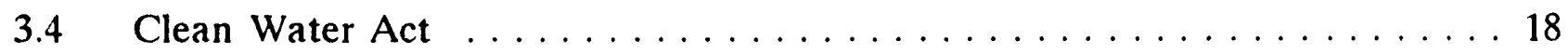

3.5 Safe Drinking Water Act . . . . . . . . . . . . . . . . . . 19

3.5.1 Regulation under SDWA of Chemical

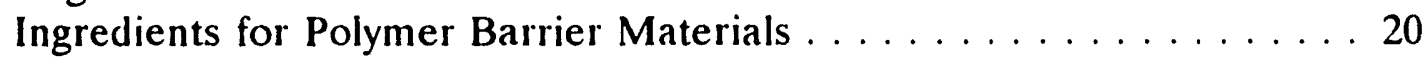

3.5.2 Applicability of Underground Injection Control

Regulations to Subsurface Barrier Installation $\ldots \ldots \ldots \ldots \ldots 21$ 


\section{TABLE OF CONTENTS (cont.)}

Page

3.6 The Emergency Planning and Community Right-to-Know Act of $1986 \ldots \ldots 23$

3.7 Summary of Health, Safety, and Environmental Issues $\ldots \ldots \ldots \ldots \ldots 24$

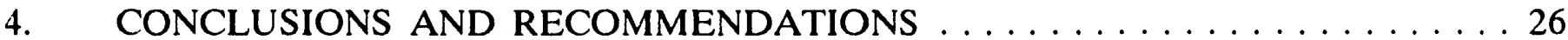

4.1 Conclusions and Recommendations Regarding EPA's Acceptance of Subsurface Barrier Technology . . . . . . . . . . . . . . . . 26

4.2 Conclusions and Recommendations Regarding Health, Safety,

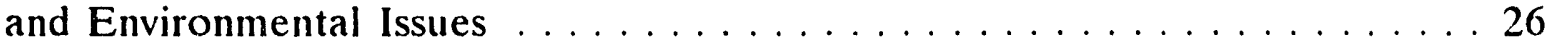

APPENDIX A - BARRIER PLACEMENT TECHNOLOGIES . . . . . . . . . . . 29

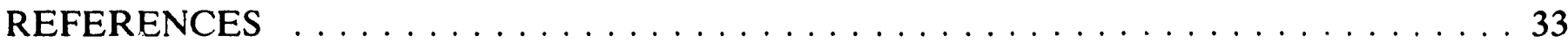




\section{LIST OF FIGURES}

Page

Figure 1. Schematic of Subsurface Barrier $\ldots \ldots \ldots \ldots \ldots \ldots \ldots \ldots$

Figure 2. Top and Cross-Sectional Views of "Keyed" Slurry Wall . . . . . . . 6

Figure 3. Cross-Sectional View of "Hanging" Slurry Wall $\ldots \ldots \ldots \ldots \ldots \ldots$

Figure 4. Schematic of Grout Curtain Around Waste Site . . . . . . . . . 30

\section{LIST OF TABLES}

Page

Table 1. Chemical Names Searched for in Code of Federal Regulations and Federal Register ...................... 13

Table 2. Organic Polymer Barrier Ingredients Cited in CFR $1910.1000 \ldots \ldots .15$ 


\section{EXECUTIVE SUMMARY}

One of the options for control of contaminant migration from buried waste sites is the construction of a subsurface barrier that consists of a wall of low permeability material. The barrier material should be compatible with soil and waste conditions specific to the site and have as low an effective diffusivity as is reasonably achievable to minimize or inhibit transport of moisture and contaminants. In this report we will address the regulatory issues associated with the use of non-traditional organic polymer materials as well as the use of soil-bentonite or cement-bentonite mixtures for such barriers, but we will consider barriers constructed from these latter materials to be a regulatory baseline. The regulatory issues fall into two categories. The first category consists of issues associated with the acceptability of such barriers to the Environmental Protection Agency (EPA) as a method for achieving site or performance improvement. The second category encompasses those regulatory issues concerning health, safety and the environment which must be addressed regarding barrier installation and performance, especially if non-traditional materials are to be used.

EPA has generally been flexible in its acceptance of any particular remediation technology for the cleanup of inactive hazardous waste disposal sites under CERCLA as long as the technology in question will result in attainment of the remediation standards specified therein. EPA guidance documents describe several kinds of subsurface barriers for controlling the movement of groundwater and/or contaminants at inactive waste disposal sites. The most commonly used subsurface barriers are slurry walls, particularly soilbentonite slurry walls, but cement-bentonite or concrete slurry walls, grouted barriers, and sheet metal piling cut-offs have also been used for the same purpose, and grouted horizontal barriers have been used to seal the bottoms of contaminated sites. We infer from this that EPA considers subsurface barrier technology to be an acceptable method of achieving such control.

Typical grouting materials, either alone or in combination, are hydraulic cements, clays, bentonite, and silicates. Organic polymer grouts, while constituting only a small fraction of the grouts in use, are also addressed in EPA guidance documents. EPA's viewpoints and requirements on such grout materials will be indicative of EPA's acceptance of organic polymers for barriers. Of particular importance for barriers constructed from fluids which are supposed to set in-situ is the chemical compatibility of the material with the wastes, leachates and geology with which it is likely to come in contact. EPA emphasizes this compatibility in its guidance documents, noting that thorough characterization of the waste, leachate, barrier material chemistry, and site geochemistry as well as compatibility testing the barrier material with the likely disposal site chemical environment are all required. Furthermore, EPA requires that the potential release of toxic barrier material constituents be addressed as part of the characterization and testing. This characterization and testing applies to both traditional bentonite- and portlandcement-based materials as well as to the non-traditional organic polymer materials. 
Because there can be problems of cracking, durability, and chemical compatibility of conventional portland cement or bentonite grouts, the DOE has undertaken several studies of advanced polymer systems for use in subsurface barriers at buried waste sites and underground storage tanks. The systems under consideration are polymer concretes -methacrylates, polyester styrenes, vinyl ester styrene, furfuryl alcohol, and polyacrylic acid - as well as modified sulfur concrete. These polymer systems employ a wide variety of chemicals as monomers, promoters, catalysts, and additives. These chemical ingredients are regulated under several Federal health, safety, and environmental rules. These rules include Occupational Safety and Health Administration (OSHA) rules under Title 29 and air, water, notification, and information rules administered by the EPA under Title 40. In order to ascertain which of these rules might apply to these chemical ingredients, we utilized the LEXIS-NEXIS database to search for the chemical names and Chemical Abstracts Service Registry numbers of these ingredients in the Federal Register for the last ten years and in the most recent Code of Federal Regulations.

The use of polymeric materials in the construction industry has been accomplished with full compliance with the applicable health, safety, and environmental regulations. Therefore, we anticipate that such compliance is achievable when using these materials as subsurface barriers, the installation of which is essentially a construction operation. With the possible exception of the Safe Drinking Water Act (SDWA), the regulatory environment should be the same as that for utilizing these materials in building a road or in installing subsurface barriers for diverting groundwater around building foundation construction activities. We emphasize that there have been no regulatory roadblocks to such uses of these materials. Applicability of the SDWA to use of these materials in DOE site remediation will need to be determined on a site-specific basis, but if a site-specific analysis shows that direct application of a drinking water standard for groundwater protection is not justified based on anticipated risk to the public, then DOE may request an exemption, variance, or alternative concentration limit. We expect that for most, if not all cases, an assessment will result in a finding of no significant impact under the SDWA.

We emphasize that while the chemical ingredients for the non-traditional barrier materials are subject to these regulations, the installation of barriers using these materials may be exempt from at least some of the environmental regulations for a variety of reasons. While these exemptions could be justified on a generic level for barrier installation operations if typical quantities of materials and emissions from unit operations are known, generic exemption from the water quality standards and from underground injection control regulations is not likely and will have to addressed on a site-specific and barrier-specific basis; we note that barriers constructed from traditional materials are subject to these regulations as well.

Regarding the air contamination limitations under occupational safety and health regulations, installation of barriers using the traditional bentonite- or portland-cementbased materials will require controls or protective measures regarding air contamination, at least with regard to airborne dust and particulates. In any case, we do not see compliance with these regulations to be an unduly onerous burden since compliance will likely involve standard industrial safety practices. 


\section{ACKNOWLEDGMENT}

The authors would like to thank Kathryn Lancaster for her efforts in conducting the search of the LEXIS-NEXIS database. 


\section{INTRODUCTION}

One of the options for control of contaminant migration from buried waste sites is the construction of a subsurface barrier that consists of a wall of low permeability material. Subsurface barriers will improve remediation performance by removing pathways for contaminant transport due to groundwater movement, meteorological water infiltration, vaporand gas-phase transport, transpiration, etc. Subsurface barriers may be used to "direct" contaminant movement to collection sumps/lysimeters in cases of unexpected remediation failures or transport mechanisms, to contain leakage from underground storage tanks, and to restrict in-situ soil cleanup operation and chemicals. (See, for example, Figure 1.) They may be used alone or in combination with techniques such as groundwater pumping, subsurface drains, and in-situ biological or chemical treatment methods. Slurry walls are the most commonly used subsurface barriers because they are relatively inexpensive, but grouted barriers such as grout curtains and sheet piling cut-off barriers are also used. ${ }^{\prime}$ The purpose of this report is to identify the regulatory issues and assumptions associated with the use of barriers in the vadose zone to improve the performance of buried waste sites.

The barrier material should be compatible with soil and waste conditions specific to the site and have as low an effective diffusivity as is reasonably achievable to minimize or inhibit transport of moisture and contaminants. Portland cement grout curtains have been used for barriers around waste sites. However, large castings of hydraulic cements invariably result in cracking due to shrinkage and thermal stresses induced by the hydration reactions. For this and other reasons other low permeability, high integrity materials are being investigated through the DOE's integrated demonstrations. BNL is currently investigating advanced polymer materials for subsurface barriers. In this report we will address the use of non-traditional organic polymer materials as well as the use of soil-bentonite or cement-bentonite mixtures for such barriers, but, because of the widespread use and general acceptance of the traditional bentonite-based mixtures, we will consider barriers constructed from these latter materials to be a regulatory baseline.

The regulatory issues fall into two categories. The first category consists of issues associated with the acceptability of such barriers to the Environmental Protection Agency (EPA) as a method for achieving such improvement. Therefore, in the next section of this report (Section 2) we describe several of the barrier technologies and consider EPA's comments and concerns regarding them. Section 2 includes a discussion of the EPA's acceptance of the use of the "baseline" traditional materials for barriers.

The second category encompasses those regulatory issues concerning health, safety and the environment which must be addressed regarding barrier installation and performance, especially if non-traditional materials are to be used. Since many of EPA's concerns regarding subsurface barriers focus on the chemicals used during installation of these barriers, in the third section of the report we discuss the results of a search of the Federal Register and the Code of Federal Regulations for references in Titles 29 and 40 pertaining to key chemicals likely to be utilized in installing non-traditional barrier materials. We also discuss here EPA's injection well regulations, which may apply to installation of subsurface barriers constructed from either traditional or non-traditional 


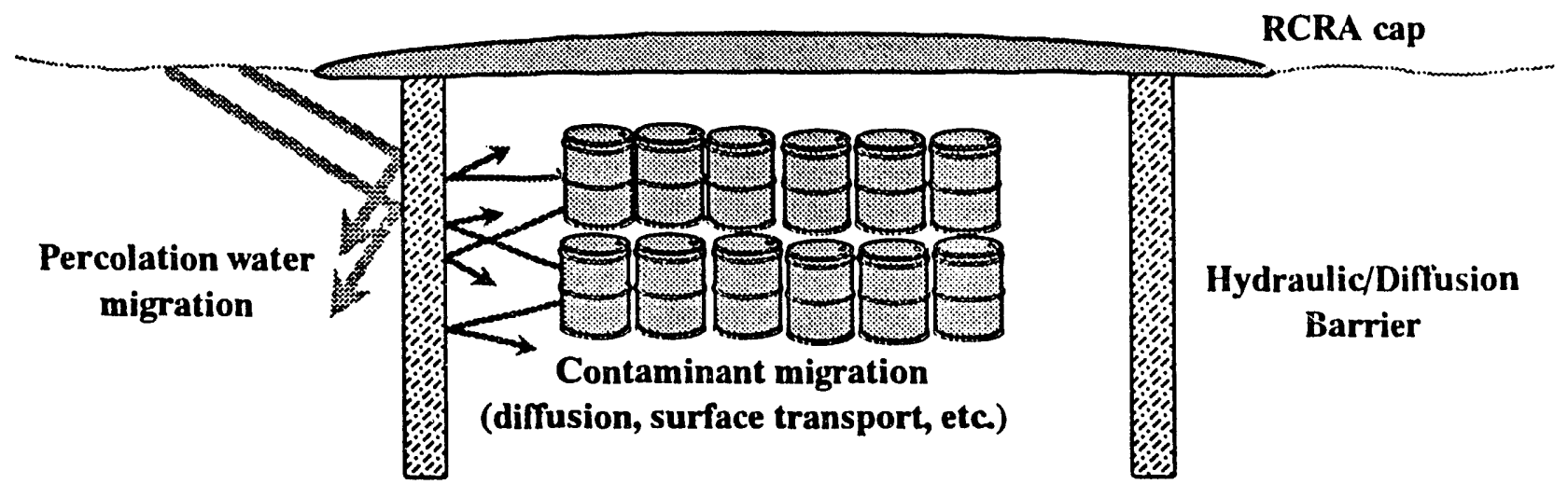

Figure 1. Schematic of Subsurface Barrier. 
materials are used. [Title 29, Labor, includes Occupational Safety and Health Administration regulations and Title 40 is Protection of the Environment.]

In the fourth and final section, we provide our conclusions on the use of barriers to improve buried waste site performance and our recommendations regarding the use of nontraditional materials for constructing such barriers.

\section{USE OF SUBSURFACE BARRIERS FOR CONTROLLING GROUNDWATER FLOW}

EPA has generally been flexible in its acceptance of any particular remediation technology for the cleanup of inactive hazardous waste disposal sites under the Comprehensive Environmental Response, Compensation, and Liability Act (CERCLA) as long as the technology in question will result in attainment of the remediation standards referred to in Section 121(d) of that Act. Section 121(b) of CERCLA provides the basis for this flexibility:

"The President [presumably via the Administrator and staff of the EPA| shall conduct an assessment of permanent solutions and alternative treatment technologies or resource recovery technologies that, in whole or in part, will result in a permanent and significant decrease in the toxicity, mobility, or volume of the hazardous substance, pollutant, or contaminant. In making such an assessment, the President shall specifically address the long-term effectiveness of the various alternatives. ... The President may select an alternative remedial action meeting the objectives of this subsection whether or not such action has been achieved in practice at any other facility or site that has similar characteristics. In making such a selection, the President may take into aceontht the degree of suppont for such remedial action by parties interested in such site."2 [Italics added.]

As a practical matter, it is not the President but EPA and the "parties interested in such site" (e.g., governmental officials, private industry, and concerned citizens -- namely, the stakeholders) who will be involved in assessing, selecting, and implementing the remediation technologies at any given facility or site. The selection of cleanup options under CERCLA is part of a larger process -- the "Superfund Process" -- which involves the following steps: ${ }^{2}$

Preliminary Assessment

Site Inspection

Remedial Investigation (RI)

Feasibility Study (FS)

Record of Decision (ROD)

Remedial Design

Remedial Action 
The selection of a remediation technology is dependent on the RI/FS portion of this process. The RI emphasizes data collection and site characterization for the purpose of defining the nature and extent of contamination at the site. The FS emphasizes data analysis and decision making using the RI data to develop response objectives and alternative remedial responses which are evaluated for engineering feasibility, public health protection, environmental impacts, and costs.'

In order to assist the stakeholders in familiarizing themselves with the range of remedial technologies available, their applications and limitations, their major design and construction considerations, and their approximate costs, EPA has published various documents, often termed "handbooks" or "technical bulletins." These are not intended as regulatory promulgations with regard to the technologies addressed but as guidance documents indicating EPA's acceptance of particular technological solutions under appropriate site-specific conditions; this means two things: (1) the technologies described in these documents still need to be evaluated for their applicability to any specific facility or site needing remediation and (2) technologies other than those mentioned in these documents may be considered although they may require more supporting technical justification than those mentioned in the documents. In this section of the report we will use several of these guidance documents to demonstrate EPA's acceptance of subsurface barriers as an alternative remedial technology for containment of contamination and reduction of future potential migration of waste constituents.

Subsurface barriers constitute a subset of one of four categories of remedial technologies for controlling groundwater contamination. These categories are:

(1) groundwater pumping involving extraction or injection of water,

(2) subsurface drains for intercepting groundwater,

(3) in-situ treatment to remove or attenuate contaminants in place beneath the surface, and

(4) low permeability barriers constructed underground to divert groundwater flow or minimize leachate generation and plume movement.

These technologies may be used in combination as well as alone for controlling the movement of groundwater contamination.

EPA has considered subsurface barriers to be among the technologies potentially applicable to remediation of waste sites. For example, in an EPA handbook ${ }^{1}$ intended for use as a basic reference tool on remedial action, EPA devotes a whole section to subsurface barriers consisting of low permeability cut-off walls or diversions which are installed below ground to contain, capture, or redirect groundwater flow in the vicinity of a site. According to this handbook, the most commonly used subsurface barriers are slurry walls, particularly 
soil-bentonite slurry walls, but cement-bentonite or concrete slurry walls, grouted barriers, and sheet metal piling cut-offs have also been used for the same purpose, and grouted horizontal barriers have been used to seal the bottoms of contaminated sites. The following two subsections (2.1 and 2.2) discuss slurry walls and grouted barriers in more detail; the final subsection (2.3) addresses EPA's acceptance of subsurface barrier technology.

\subsection{Slurry Walls}

A recent (October 1992) EPA Engineering Bulletin ${ }^{3}$ describes the slurry wall technology. According to this bulletin, slurry walls are applicable at Superfund sites where residual contamination needs to be isolated at its source. For example, they may be used where the waste mass is too large for practical treatment, where residuals from the treatment are landfilled, and where soluble and mobile constituents pose an imminent threat to a source of drinking water. Low-permeability slurry walls may serve one or more of the following purposes: redirect groundwater flow, contain contaminated materials and contaminated groundwater, and provide increased subsurface structural integrity. Traditional soil-bentonite or cement-bentonite slurry walls can be instalied quickly, and, since the use of these barriers in the construction industry for dewatering building foundations and excavations is well established, the construction requirements and practices associated with their installation are well understood. (See, for example, a handbook on slurry trenches published by the EPA in $1984 . .^{4}$ ) For this reason, we will consider the traditional slurry walls as a baseline barrier technology for the purposes of this regulatory analysis.

As an example of EPA's acceptance of the slurry wall technology, the bulletin notes that in FY 1989, there were 26 records of decision (RODs) specifying the use of slurry walls as part of the remedial action. Their construction is considered a well-established technology for effectively isolating wastes and containing the migration of hazardous constituents. They may be implemented rather quickly in conjunction with other remedial actions, but long-term monitoring is needed to evaluate their effectiveness. ${ }^{3}$

Depending on the site conditions, the wall can be "keyed" into the bedrock or aquitard (Figure 2) or can be a "hanging wall" which extends below the water table to capture chemical "floaters" (Figure 3). The bulletin, however, mentions two examples of slurry wall installations which were not keyed into the underlying aquitard, in one case by intent, but which, in conjunction with other technologies, nevertheless resulted in significant reductions in release of contaminants."

One caution which the EPA literature on slurry walls mentions is the detrimental effect which certain chemicals can have on slurry walls containing bentonite mixtures. ${ }^{1.3,4}$ Certain chemicals can increase the permeability of bentonite mixtures or even result in dissolution of the material. Some organic fluids result in desiccation and cracking of the 

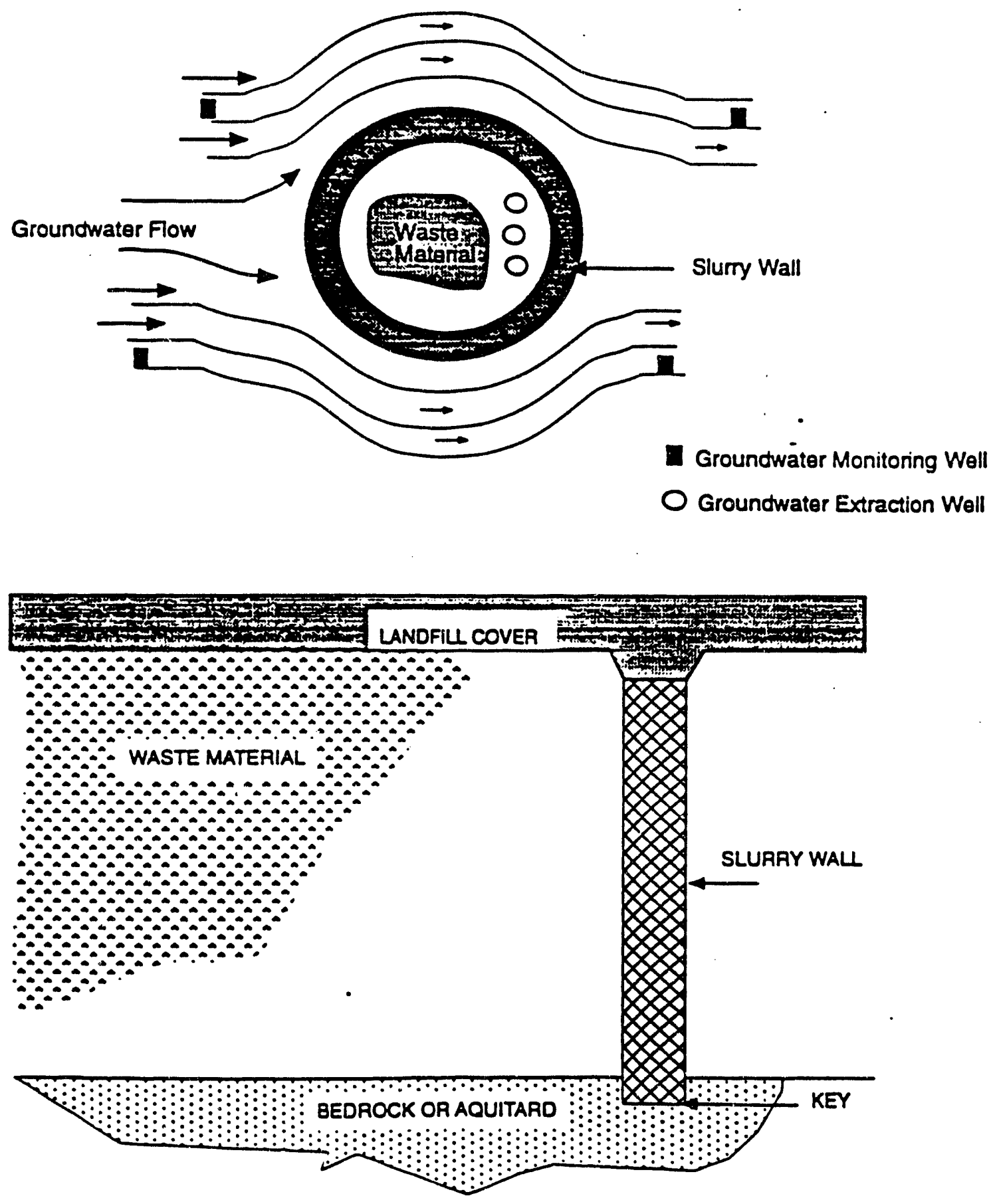

Figure 2. Top and Cross-Sectional Views of "Keyed" Slurry Wall. ${ }^{3}$ 


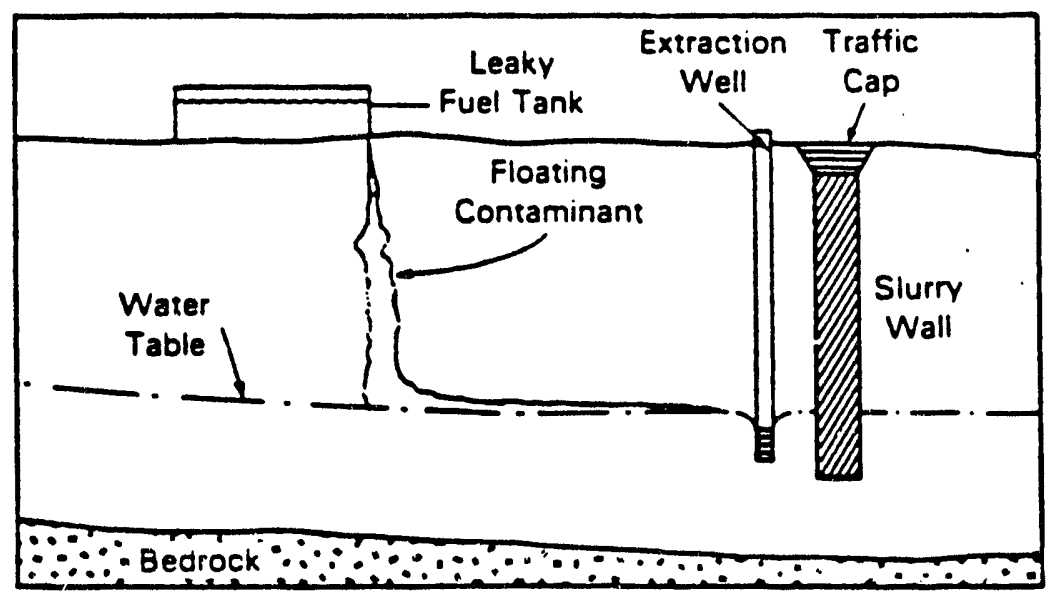

Figure 3. Cross-Sectional View of "Hanging" Slurry Wall.4 
bentonite material. In any case, the EPA literature emphasizes the necessity of compatibility testing between the slurry wall material and the chemicals it is likely to come in contact with. As we shall see in the next subsection, these precautions also apply to other barrier materials. A description of slurry wall construction is given in appendix $A$.

\subsection{Grouted Barriers'}

Grouting refers to the injection into a rock or soil mass of fluids which reduce the water flow and strengthen the formation by solidifying or setting in place. Grouts may be injected to form subsurface barriers in unconsolidated materials. A subsurface barrier constructed in this manner is termed a grout curtain.

Typical grouting materials, either alone or in combination, are hydraulic cements, clays, bentonite, and silicates. Organic polymer grouts, while constituting only a small fraction of the grouts in use, are of greatest interest since this will be indicative of the EPA's viewpoints and requirements on using advanced polymers for barriers. The organic: polymer grouts addressed in the EPA handbook on remedial action are:

- Acrylamide grouts.

- Phenolic grouts.

- Urethane grouts

- Urea-formaldehyde grouts

- Epoxy grouts

- Polyester grouts

Acrylamide grouts have had widespread use for structural support and seepage control in mines, soil consolidation for structural foundations, and water control and soil consolidation for tunnels, wells, and mines. Grout curtains are among the specific applications of these grouts. ' Because acrylamide grouts have been banned in Japan as a result of several cases of aquifer contamination -. acrylamide is a neurotoxin and the polymerization accelerator, dimethylaminopropionitrile, is a suspected carcinogen -- their use in this country has virtually ceased. Several relatively non-toxic acrylate grouts have effectively replaced them." The newer acrylates and polyesters are the most likely candidates for barrier applications.

As with grouts formulated from more traditional cementitious or clayey materials, the compatibility of these organic polymer grouts with the hazardous wastes, soil chemistry and leachates at any particular site needs to be ascertained before selecting a grout 
formulation. A thorough characterization of the waste and grout chemistry, as well as the site geochemistry, is needed.' The EPA remedial action handbook' notes that uniess the setting reactions of grouts are carefully controlled, there is the possibility of release into the ground of unreacted constituents.

The EPA remedial action handbook concludes that no detailed assessment of the performance or reliability of grout curtains for use at hazardous waste sites is possible since this is a specialty technology seldom applied to hazardous waste sites. ' Brief descriptions of several grout curtain placement technologies are given in appendix $A$.

\subsection{Conclusions on EPA's Acceptance of Subsurface Barriers}

EPA guidance documents describe several kinds of subsurface barriers for controlling the movement of groundwater and/or contaminants at inactive waste disposal sites. We infer from this that EPA considers subsurface barrier technology to be an acceptable method of achieving such control. The selection of subsurface barriers for any given site needing remediation and the selection of a particular barrier technology must, however, be done by means of the Superfund Process, with special emphasis on the remedial investigation and feasibility study portions. Of particular importance for barriers constructed from fluids which are supposed to set in-situ is the chemical compatibility of the material with the wastes, leachates and geology with which it is likely to come in contact. EPA emphasizes this compatibility in its guidance documents, noting that thorough characterization of the waste, leachate, barrier material chemistry, and site geochemistry as well as compatibility testing the barrier material with the likely disposal site chemical environment are all required. Furthermore, EPA requires that the potential release of toxic barrier material constituents be addressed as part of the characterization and testing. This requirement for characterization and testing applies to both traditional and non-traditional materials.

The EPA remedial action handbook', however, while stating that such characterization and testing will be necessary before using either category of materials, provides no guidance as to the actual tests which must be conducted. For preliminary guidance in these matters we must instead refer to the EPA slurry trench construction handbook which states the following:

"To test the compatibility of compounds contained in the groundwater with the material used in the construction of slurry walls, a series of laboratory tests should be performed. Since there are, as yet, no standard tests and testing procedures established for determining the compatibility of chemicals with slurry walls, the types of tests and their associated testing procedures can vary widely between laboratories. [Emphasis added.] 
This handbook then specifies the following four test methods which are applicable to bentonite:

viscosity of the bentonite slurry,

filter press test consisting of pressure filtration of the slurry to ascertain whether fluid loss to the filtrate is within prescribed limits,

permeability of a soil bentonite mixture saturated with leachate compared to the permeability of one saturated with water, and

mineralogical examination.

These tests methods are intended to determine whether groundwater contaminants affect the properties of the bentonite. While these tests are not standardized for the purpose of evaluating slurry walls or grouts, the procedures have been standardized for other purposes, e.g., evaluation of bentonite-based petroleum drilling fluids.

Based on our literature review, EPA has not investigated test methods for nontraditional barrier material compatibility with subsurface conditions or for leaching of toxic constituents from the barrier material into the soil, which in this case are unpolymerized toxic monomers such as styrene. Compatibility testing of these materials with the soil and contaminated water will need to be done on a site-specific basis by measuring selected parameters, e.g., permeability, chemical resistivity, and indicators of structural integrity of a monolithic barrier wall such as compressive, tensile, and flexural strengths, in the presence of soil and water from the site. Whether toxic constituents can leach from the barrier can be determined by leach tests on the solidified final product: one vendor uses the California leach test on the final solidified product to detect the leaching of toxic polymerization promoters such as cobalt and dissolves the final solidified product in an appropriate solvent and analyzes for monomers in order to ascertain the amount of unpolymerized monomer remaining. We would suggest adapting some standardized leach test and analyzing the leachate from a solidified final product for toxic unreacted reactants and leachable promoters and catalysts.

\section{HEALTH, SAFETY AND ENVIRONMENTAL ISSUES RELATED TO SUBSURFACE BARRIER TECHNOLOGY}

Since EPA approves of the technology of subterranean barriers for remedial actions the next question is what material are deemed acceptable for barrier construction. As

\footnotetext{
"Telephone conversation between John Heiser, BNL, and George Frost, 3M, on April 19, 1993.
} 
mentioned earlier there can be problems of cracking, durability, and chemical compatibility of conventional portland cement or bentonite grouts. The DOE has undertaken several studies of advanced polymer systems for use in subsurface barriers at buried waste sites and underground storage tanks. The systems under consideration are polymer concretes and modified sulfur concrete. These polymer systems employ a wide variety of chemicals as monomers, promoters, catalysts, and additives. These chemical ingredients are regulated under several Federal health, safety, and environmental rules. These rules include Occupational Safety and Health Administration (OSHA) rules under Title 29 and air, water, notification, and information rules administered by the EPA under Title 40 . In order to ascertain which of these rules might apply to these chemical ingredients, we utilized the LEXIS-NEXIS database to search for the chemical names and Chemical Abstracts Service (CAS) Registry numbers of these ingredients in the Federal Register for the last ten years and in the most recent Code of Federal Regulations. The following subsections provide an overview of advanced barrier materials and these rules as they may potentially apply to the installation of barriers constructed from such non-traditional materials as well as to those constructed from the more traditional portland-cement- or bentonite-based materials.

\subsection{Materials}

Many of the advanced polymer systems considered for barriers are classified as polymer concretes. Polymer concrete is defined as an aggregate mixed with a liquid monomer or resin (binder) which is converted in place, to form a hard polymer monolith. This material can be mixed and cast in the field. The list of candidate binders included in our search have or are being considered by DOE programs for subterranean barriers. Selection was based on durability of the polymer and chemical and physical characteristics of the resin (i.e., viscosity). These included methacrylates, vinyl-ester styrene, polyester styrene, furfuryl alcohol, and polyacrylic acids. These polymers require a chemical reaction for solidification to occur.

The polymerization of unsaturated monomers such as polyester-styrene is typically a chain reaction. Polymerization can be initiated by the action of a free radical on a monomer molecule, which leads to polymer chains consisting of thousands of monomer molecules. Free radicals can be formed by the decomposition of a relatively unstable material called an initiator or a catalyst. Benzoyl peroxide is a commonly used initiator. When subjected to heat or in the presence of a promoter, the peroxide molecule splits at the $0-0$ bond to form two free radicals that have unpaired electrons and are thus very reactive.

Promoters can be used instead of temperature for ambient temperature curing of catalyzed monomer systems. Promoters (also called accelerators) are chemical compounds that induce the decomposition of a peroxide catalyst by breaking the $0-0$ bond. This 
reaction can take place over a wide temperature range, depending on the promoter-catalyst system used. This is the preferred method for in-situ applications.

Cure time is dependent upon temperature, promoter-catalyst combination and concentration, and admixtures that may retard or enhance the set. The reaction is exothermic and results in an autoaccelerating reaction that can be properly controlled. Thermosetting polymers have been developed to solidify radioactive, mixed, and hazardous waste. ${ }^{0.7 .8 .9}$

The second type of advanced polymer system considered for barriers is a thermoplastic, modified sulfur cement. Thermoplastics become liquid when heated above their melting points and can be mixed with aggregate, soil, waste, etc., and upon cooling form a hard monolithic solid. Full strength is achieved in hours rather than weeks as compared to hydraulic cements. Thermoplastics can be reheated and reformed after they have "set".

The following is a brief synopsis of the polymer systems and the additives (e.g. promoter/catalyst) required for barrier construction. A summary of the chemicals considered in the regulatory search is given in Table 1. The regulations effecting the use of these chemicals is outlined in later subsections.

\subsubsection{Methacrylates}

Methacrylate monomers are a low viscosity, inexpensive, and commonly used family of polymers. The methacrylate used by BNL is a modified high molecular weight methacrylate. The system consists of dicyclopentadienyl methacrylate and iso-octyl acrylate and is polymerized using a cobalt octoate promoter (reducing agent) and cumene hydroperoxide initiator (oxidative catalyst).

\subsubsection{Polyester Styrene}

Polyester styrenes (PES) are among the most widely used thermosetting resins. The basic components of a PES polymer consist of a mixture of a linear polyester resin and styrene monomer. Chemical and physical characteristics of the final polymer are dependent on the choice of polyester resin and styrene content. Based on the alkali nature of many DOE site soils and the Hanford underground storage tank supernatants BNL selected an alkali resistant modified bisphenol fumarate resin using a $6 \%$ cobalt naphthenate (CoN6) solution as the promoter and methyl ethyl ketone peroxide (MEKP) as the initiator. 
Table 1. Chemical Names Searched For in Code of Federal Regulations and Federal Register

\section{CHEMICAL NAME}

benzoyl peroxide

$\mathrm{N}, \mathrm{N}$-dimethylaniline

styrene

vinyl ester resin

cobalt octoate

cumene hydroperoxide

cumene

dicyclopentadienyl methacrylate

iso-octyl acrylate

mineral spirits

neodecanoate

bisphenol fumarate resin

cobalt naphthenate

methy ethyl ketone peroxide (2-butanone peroxide)

ammonium persulfate (ammonium peroxydisulfate)

2-hydroxypropyl acrylate

magnesium acrylate

$\mathrm{N}, \mathrm{N}$ '-methylenebisacrylamide

triethanolamine $\left(2,2^{\prime}, 2^{\prime \prime}\right.$-nitrilotriethanol)

furfuryl alcohol

p-toluenesulfonic acid

zinc chloride
CAS NUMBER

94-36-0

121-69-7

$100-42-5$

$68002-44-8$

136-52-7

80-15-9

98-82-8

51178-59-7

29590-42-9

8032-32-4

27253-31-2

61789-51-3

1338-23-4

7727-54-0

999-61-1

110-26-9

102-71-6

98-00-0

6192-52-5

104-15-4

7646-85-7 


\subsubsection{Vinyl Ester Styrene}

Vinyl ester styrene (VES) polymers are extremely durable both chemically and physically. These polymers have been used to encapsulate radioactive waste and in a wide variety of applications calling for resistance to harsh chemicals. " " The polymerization occurs using an oxidation-reduction reaction. Typically dimethylaniline (DMA) promoter is used in conjunction with a $40 \%$ benzoyl peroxide (BPO) catalyst solution.

\subsubsection{Furfuryl Alcohol}

Furfuryl alcohol (FA) has a low viscosity, low vapor pressure, low flammability, and is soluble in water. This material produces a very resistant polymer using cheap and environmentally innocuous components. FA has been used in the fabrication of polymer concrete pipes, as an organic cementing and sand consolidating material in oil wells, floor coatings, and chemically resistant containers. Polymerization of furfuryl alcohol occurs through a condensation reaction using a strong acid catalyst. For this study the catalyst used was p-toluenesulfonic acid.

\subsubsection{Polyacrylic Acid}

Polyacrylic acid, under the trade name AC-400 (Geochemical Corporation) is among the most widely used hydraulic barrier materials for construction applications in the United States. This material, a magnesium acrylate, produces a soft gel rather than a hard solid with typical compressive strengths of 50 psi. AC-400 is commonly used to seal sewer pipe leaks and to stop water infiltration at construction sites. Acrylate grouts have been shown to have low water permeabilities and to be resistant to a large number of chemicals. ${ }^{2}$ Acrylate grout gels typically contain $80-90 \%$ water and are extremely sensitive to wet-dry and freeze-thaw cycling. Such high water content gels work best in $100 \%$ humidity or water submerged conditions. The soft gels are also prone to creep fatigue failures and can fail with loadings as low as $20 \%$ of the unconfined compressive strength (UCS). ${ }^{13}$ Acrylate grouts behave similarly to the acrylamide grouts and have quickly replaced the latter due to lower toxicities (1/100th of acrylamide grouts). Polymerization occurs using triethanolamine (TEA) catalyst and ammonium persulfate (AP) initiator. Gel time is variable from 5 seconds to 1 hour and can be adjusted by adding potassium ferricyanide $\left(\mathrm{KFe}[\mathrm{CN}]_{6}\right.$ ), an inhibiting agent. $\mathrm{AC}-400$ was investigated due to the high use in construction, existing placement technologies, and interest from several outside parties.

\subsubsection{Modified Sulfur Cement}

Modified sulfur cement (MSC) is a sulfur polymer developed by the U.S. Bureau of Mines to utilize surplus sulfur. ${ }^{14} \mathrm{MSC}$ is a thermoplastic material that melts at $119^{\circ} \mathrm{C}$. 
Sulfur concrete offers excellent chemical resistance to strong acids and salts and is relatively inexpensive. It have been used for construction of chemical vats, road repairs, and is a candidate for encapsulating radioactive, hazardous, and mixed wastes. MSC is formed by reacting elemental sulfur with dicyclopentadiene and oligomers of cyclopentadiene. This modification to elemental sulfur suppresses a crystalline phase change that occurs as sulfur cools below $95.6^{\circ} \mathrm{C}$. In unmodified sulfur, the monoclinic form of sulfur changes to the orthorhombic form with a resultant density increase and an introduction of stresses. Such residual stresses make sulfur susceptible to shock damage by impact or thermal changes.

\title{
3.2 OSHA Standards - Air Contaminants
}

Almost all of the chemical ingredients used for the non-traditional materials considered in this report are re,ulated under 29 CFR Section 1910.1000, Air Contaminants. Table 2 provides a list of those chemical ingredients which, according to the database search, are cited in Section 1900.1000. Transitional air exposure limits for these chemicals were in effect as of July 1, 1992, the most recently published version of Title 29, but most of these were due to be replaced by the Final Rule Limits in Section 1900.1000 effective December 31, 1992, unless other limits had been published as a Final Rule in the Federal Register.

Table 2. Organic Polymer Barrier Ingredients Cited in 29 CFR 1910.1000

\author{
benzoyl peroxide \\ $\mathrm{N}, \mathrm{N}$-dimethylaniline \\ styrene \\ cumene \\ iso-octyl acrylate \\ mineral spirits \\ 2-hydroxypropyl acrylate \\ furfuryl alcohol \\ zinc chloride
}

In order to achieve compliance with these limits, administrative or engineering controls must first be determined or implemented whenever feasible. If it is not feasible to achieve full compliance by such controls, protective equipment or other protective measures shall be used to keep employee exposure to air contaminants within the 
prescribed limits. Equipment and technical measures used for this purpose must be approved by a competent industrial hygienist or other technically qualified person.

\subsection{Clean Air Act $^{15}$}

On November 15, 1990, President Bush signed into law sweeping revisions of the Clean Air Act (CAA). Here we consider some of the provisions of the CAA amendments which may be important for construction at DOE remediation sites of subterranean barriers in the vadose zone.

\subsubsection{Standards of Performance for New Stationary Sources}

The New Source Performance Standards (NSPS) are presented in 10 CFR Part 60. The NSPS address standards of performance under the Clean Air Act for new stationary sources, namely, potential sources of air emissions constructed or modified after the date of publication of an applicable standard in Part 60. The subparts after some introductory material are organized by industrial category, e.g., synthetic organic chemicals, industrial surface coatings: cans, dry cleaning, graphic arts. $\$ 60.16$ provides a "Priority List" of industries, some of which are not addressed in Part 60; EPA is still working on the standards for these. Grouting operations are not explicitly included either in the list of industries in $\$ 60.16$ or in the subparts organized by industrial category. EPA could, however, add grouting operations and/or installation of subsurface barriers utilizing organic polymers to its list of industries or could expand the definition of one of the currently listed industries to include these operations.

The following industrial stationary source categories, for example, if defined rather broadly, could conceivably encompass polymer grouting:

Subpart Kb --- Standards of Performance for Volatile Organic Liquid Storage Vessels (Including Petroleum Liquid Storage Vessels) for which Construction [missing words] or Modification Commenced after July 23, 1984. The CFR/FR database search found no mention in this subpart of any of the chemical ingredients for polymer grouts.

Subpart VV -.- Standards of Performance for Equipment Leaks of Volatile Organic Compounds (VOCs) in the Synthetic Organic Chemicals Manufacturing Industry. The CFR/FR database search found the following chemical ingredients for various polymer grouts tabulated in $\$ 60.489$ of this subpart:

$\mathrm{N}, \mathrm{N}$-dimethylaniline

styrene

cumene hydroperoxide 


\author{
cumene \\ isn-octyl acrylate \\ p-toluenesulfonic acid \\ triethanolamine
}

Note that two of these, iso-octyl acrylate and triethanolamine, may have appeared only in proposed revisions to this subpart and are not listed in the currently available (July 1, 1992) version of the CFR.

Subpart DDD --- Standards of Performance for VOC Emissions from the Polymer Manufacturing Industry. The CFR/FR database search found one polymer grout chemical ingredient tabulated in $\$ 60.561$ of this subpart, namely, styrene.

The NSPS regulations set minimum Federal emission limitations on classes of facilities. The NSPS is set at the level which reflects the degree of control achievable through the application of the best system of continuous.emission reduction which has been adequately demonstrated for that category of sources. The NSPS must consider the cost of achieving such emissions reductions and any non-air quality health and environmental impact and energy requirements.

\title{
3.3.2 National Emission Standards for Hazardous Air Pollutants
}

Congress expanded the number of hazardous air pollutants (HAPs) from eight to 189 and has required the EPA Administrator to periodically review and revise this list by adding to it other pollutants which may adversely affect human health and the environment. This list, in Sec. 112 of the amended CAA, includes the following chemical substances (with their CAS registry numbers) of relevance to polymer-based grouts: cumene (98828), N,Ndimethylaniline (121697), and styrene (100425). The approach to regulating the HAPs has shifted from health-based, substance-specific standards to technology-based standards applicable to categories of emission sources rather than to the substances emitted. More sources of HAPs, including small sources, will come under the operating permit requirements because of the new definitions of "major source" and "area source" (i.e., those which are not major sources). Major sources are those with the potential to emit (with emission controls) 10 TPY or more of any single HAP or 25 TPY or more of any combination of HAPs. While it appears that the airborne emissions from polymer grouting operations of the three chemicals just mentioned are very likely to be much less than the 10 to 25 TPY threshold levels for major sources, we note that the CAA authorizes the EPA Administrator to set lesser quantities for a major source.

The CAA amendments required EPA to promulgate first round technology-based emission standards for the HAP source categories and subcategories according to an imposed schedule starting November 15, 1992, and concluding on November 15, 2000. The first round emission standards must require the maximum achievable control technology 
(MACT), which may include measures such as emissions controls, process changes, materials substitution, and operator training and certification. Six years after enactment, EPA must evaluate the "residual risk" to public health remaining after the promulgation of the first round MACT emission standards and, if necessary, promulgate additional standards to further reduce HAP emissions. Owners or operators of stationary sources must prepare, implement and register with EPA (and a with new Chemical Safety and Hazard Investigation Board) risk management plans. Obviously, the regulations associated with these HAP source categories are in a state of flux and almost daily monitoring of the Federal Register is necessary to keep current.

The CFR/FR database search found the following chemical ingredients for various polymer grouts listed in the Federal Register for December 31, 1992 under 40 CFR Part 63, National Emission Standards for Hazardous Air Pollutants (NESHAPs):

\author{
styrene \\ cumene hydroperoxide \\ triethanolamine \\ p-toluenesulfonic acid
}

The CAA Amendments create new criminal sanctions for negligent (as opposed to "knowing") violations and establish administrative penalty mechanisms to complement the traditional civil (judicial) enforcement program. Fines and prison sentences can now be imposed against any person -- including DOE and contractor personnel -- who negligently releases any HAP covered under the NESHAPs or included on the Superfund list of extremely hazardous substances but not listed under the NESHAPs. "Knowing" releases incur more severe penalties.

We note, however, that installation of a barrier is a limited time-span operation when compared to most industrial operations covered under NSPS and NESHAPs portions of the CAA regulations. It is not clear at present that installation of barriers using polymer grouts presently is or will at some future time be covered under either the NSPS or NESHAPs regulations. We anticipate that use of polymer grouts will involve standard unit operations which will be able to meet the MACT emission standards as well as the OSHA standards covered above in Section 3.1 of this report.

\title{
3.4 Clean Water Act $^{16}$
}

The objective of the Federal Water Pollution Control Act or Clean Water Act (CWA) is (Section 101) "to restore and maintain the chemical, physical, and biological integrity of the Nation's waters." The CWA requires the EPA to establish limits called "effluent limitations" on the quantities of specific pollutants which may be discharged by municipal sewage treatment plants and industrial facilities. These limitations are based on available technologies and take into account the cost of compliance. Dischargers of these 
pollutants must operate under National Pollutant Discharge Elimination System (NPDES) permits based on these effluent limitations. If the technology-based limits are not strict enough to make waters safe for uses such as drinking, swimming, and fishing, EPA also sets limits based on water quality standards. All DOE facilities which discharge wastewaters to either a surface water body or a publicly-owned treatment system must comply with the CWA. While we do not foresee discharges to surface waters routinely resulting from installation of barriers, we provide an overview if the potential applicability of the CWA for the sake of completeness.

The CFR/FR database search found the following chemical ingredients for various polymer grouts listed under regulations promulgated under the CWA as follows:

40 CFR \$116.4 - Designation of Hazardous Substances, and

40 CFR \$117.3 - Determination of Reportable Quantities for Hazardous Substances

\author{
styrene \\ zinc chloride \\ methyl ethyl ketone peroxide
}

Subchapter N -- Effluent Guidelines and Standards,

40 CFR Part 414 - Organic Chemicals, Plastics, and Synthetic Fibers

\author{
$\mathrm{N}, \mathrm{N}$-dimethylaniline \\ styrene \\ cumene hydroperoxide \\ cumene \\ zinc chloride
}

As the titles of the sections indicate, 40 CFR Part 116 designates hazardous substances and Part 117 lists reportable quantities for discharges of these substances into surface waters. Subchapter $\mathrm{N}$ specifies effluent guidelines and standards for various industrial point source categories, most of which are not likely to be applicable to DOE or to installation of barriers. A very broad definition of the organic chemicals, plastics, and synthetic fibers industry could conceivably encompass installation of barriers using organic polymer grouts and thus render Part 414 potentially applicable to this activity.

\title{
3.5 Safe Drinking Water Act
}

The Safe Drinking Water Act (SDWA) is an environmental statute for protecting drinking water sources. Primary drinking water standards promulgated under this act are of significance to DOE because they are utilized for groundwater protection regulations under a number of other statutes, notably, the Resource Conservation and Recovery Act (RCRA) (e.g., as extract concentration limits in the definition of hazardous wastes) and the 
Superfund Amendments and Reauthorization Act (SARA) as applicable or relevant and appropriate requirements (ARARs) in National Priority List Cleanups. It is of equal importance to DOE, however, that these primary drinking water standard.s also apply to drinking water at the tap as delivered by public water supply systems. This applicability is of relevance to DOE in circumstances such as at Cak Ridge DOE facility, since this facility provides water to the city of Oak Ridge. In addition, 40 CFR 141.2 includes the definition of a "non-transient non-community water system" as a public water system which regularly serves at least the same 2.5 people for six months per year, e.g., work places and hospitals; many DOE facility water systems will meet the definition of this type of public water system and will thus come under SDWA regulations. States have primary enforcement authority under this act and may consider costs, benefits, alternatives, public interest, and the protection of human health and the environment in granting variances and exemptions from the regulations. Thus, if for a particular DOE facility a site-specific analysis shows that direct application of a drinking water standard for groundwater protection is not justified based on anticipated risk to the public, then DOE may request an exemption, variance, or alternative concentration limit. ${ }^{17}$

The installation of subsurface barriers constructed of organic polymer materials potentially falls under the SDWA in two areas. The first area involves some of the chemical ingredients used for the non-traditional organic polymer materials. As in the cases involving OSHA air contaminant standards and the Clean Air and Water Acts considered in previous sections of this report, some of these ingredients are regulated under the SDWA. The second area concerns the regulations in this act related to Underground Injection Control (UIC). These regulations were intended to mandate various prohibitions on the underground injection in wells of hazardous waste in response to the 1984 Hazardous and Solid Waste Amendments to RCRA, but the definitions in the regulations appear to include the installation of subsurface barriers (whether the materials used are iraditional bentonite and/or concrete or non-traditional organic polymers and even if no waste is injected). The following two subsections describe these two aspects of the potential applicability of the SDWA to installation of subsurface barriers at DOE sites.

\subsubsection{Regulation under SDWA of Chemical Ingredients for Polymer Barrier Materials}

The results of the CFR/FR database search indicate that styrene and zinc chloride are mentioned in several places in 40 CFR Parts 141,142, and 143, which are 'National Primary Drinking Water Regulations", "National Primary Drinking Water Regulations Implementation," and "National Secondary Drinking Water Regulations," respectively. Part 141 establishes these regulations by setting maximum contaminant levels (MCLs), monitoring and analytical requirements, and reporting, public notification, and record maintenance requirements. The $M C L$ is the maximum permissible level of a contaminant delivered at the tap to the ultimate user. Part 141 also sets maximum contaminant level goals, namely, the non-enforceable maximum level of a contaminant in drinking water at which no health effect is anticipated or known but which allows an adequate margin of 
safety. In addition, Part $1+1$ establishes treatment techniques in lieu of MCLs for specified contaminants. Other provisions of Part 141, e.g., turbidity and microbiological limits, are not of obvious direct relevance to installation of subsurface barriers although the physical stresses of the barrier installation process could conceivably result in turbidity or microorganisms entering drinking water: in any case, DOE will need to address these limits in other contexts beyond the scope of this report. (Concerns regarding turbidity or microorganisms are of relevance to subsurface barriers constructed from traditional materials as well as from organic polymers. See Section 3.4.2, which follows, on UIC.) Part 142 promulgates regulations for implementation of the regulations in Part 141. Part 143 establishes secondary regulations for contaminants affecting primarily aesthetic qualities relating to public acceptance of drinking water; these regulations are not Federally enforceable but are intended as guidelines for the states. At concentrations considerably above the levels specified in Part 143, health implications may exist in addition to aesthetic considerations.

Styrene is mentioned in the context of public notification (\$141.32), monitoring $(\$ 141.40)$, maximum contaminant level goals $(\$ 141.50)$, and variances and exemptions from the MCLs $(\$ 142.62)$. Zinc is mentioned as a secondary contaminant in Part 143. Standards for styrene, zinc, and zinc chloride (measured as zinc) are listed in Drinking Water Regulations and Health Advisories, which is a consolidated listing of information on drinking water standards and goals published periodically by EPA's Office of Water.

We note that EPA may be expanding the lists of contaminants under Parts 141, 142, and 143 so that other chemical ingredients for barrier materials may be included in future versions of these regulations.

\subsubsection{Applicability of Underground Injection Control Regulations to Subsurface Barrier Installation}

The permitting and other program requirements for UIC programs, whether run by a state or by the EPA are specified in 40 CFR Part 144. Technical criteria and standards for UIC programs are set in 40 CFR Part 146.

According to Part 144, the UIC Permit Program regulates underground injections by five classes of wells. As stated in $\$ 144.1(\mathrm{~g})(1)(\mathrm{ii})$, among the specific inclusions is the following: "Any dug hole or well that is deeper than its largest surface dimension, where the principal function of the hole is emplacement of fluids." (We are considering the "largest surface dimension" to be the width of the trench excavated for installation of the barrier rather than the largest diameter of the barrier surrounding the waste source needing remediation.) Since other "specific inclusions" in " $\$ 144.1(\mathrm{~g})(1)$ refer explicitly to injection of wastes and disposal of fluids containing hazardous waste, we infer that the injection activity described in item (ii) is not necessarily limited to injection of waste. This inference is supported by the following definitions given in $\$ 144.3$ : 
"Well injection" means the subsurface emplacement of fluids through a bored, drilled or driven well; or through a dug well, where the depth of the dug well is greater than the largest surface dimension:

a "well" means a bored, drilled or driven shaft, or a dug hole, whose depth is greater than the largest surface dimension: and

"fluid" means any material or substance which flows or moves, whether in a semisolid, liquid, sludge, gas, or any other form or state.

This inference is also supported by the classification scheme for injection wells given in \$144.6. This scheme consists of five classes of wells; Class I and Class IV wells are specifically used for hazardous or radioactive waste disposal, Class II wells are used to inject fluids associated with storage, production, or enhanced recovery of oil or natural gas, and Class III wells are those which are use to inject fluids as part of a mineral extraction operation (e.g., solution mining). All other wells, including those excavated for subsurface barrier installation fall within the catch-all Class V category, "Injection wells not included in Classes I, II, III, or IV."

Another important definition given in $\$ 144.3$ is the following:

"Contaminant" means any physical, chemical, biological, or radiological substance or matter in water." [Emphasis added.]

Note that the term "contaminant" is not limited in the definition in any way to hazardous, toxic, pathogenic, or even merely noxious contaminants! The contaminants of concern are more specifically described elsewhere in Part 144, e.g., $\$ 144.1(\mathrm{~g})$, which states that "no injection shall be authorized by permit or rule if it results in the movement of any contaminant into Underground Sources of Drinking Water (USDWs ... ), if the presence of that contaminant may cause a violation of any primary drinking water regulation under 40 CFR Part 142 or may adversely affect the health of persons ... " This is reiterated in \$144.12(a), which also states, "The applicant for a permit [in cases of interest for this report, that means DOE] shall have the burden of showing that the requirements of this paragraph are met." Later paragraphs of $\$ 144.12$ describe possible actions of the Regional EPA Director in the event a Class $V$ well may cause a violation of the primary drinking water regulations or otherwise adversely affect the health of persons; these actions include requiring an individual permit, ordering preventive or corrective actions (including closure of the injection well), or take enforcement action.

Note that these regulations apply to installation of subsurface barriers constructed from either the traditional bentonite- or portland-cement-based materials or the nontraditional organic polymer materials. Therefore, even if the chemical ingredients for the barrier material are not of concern with respect to Part 142, the physical stresses of barrier 
installation, as indicated in the previous subsection of this report (3.4.1) could result in turbidity or microorganisms entering drinking water.

\subsection{The Emergency Planning and Community Right-to-Know Act of $1986^{2}$}

The Emergency Planning and Community Right-to-Know Act was enacted as a stand-alone portion (Title III) of SARA passed in response to concerns posed by the storage and handling of toxic chemicals. These concerns resulted from the more than 2,00 deaths and serious injuries resulting from the accidental release of methyl isocyanate in Bhopal, India. To minimize the probability of such disasters in the United States, Congress imposed requirements on the states and on the regulated facilities. EPA's implementing regulations for Title III are codified in 40 CFR Parts 350, 355, 370, and 372.

Part 350 deals with trade secrecy. Part 3.55 establishes the list of extremely hazardous substances, threshold planning quantities, and facility notification responsibilities necessary for the implementation of emergency response plans; we note that none of the chemical ingredients for the organic polymer subsurface barrier materials are included in the list of extremely hazardous chemicals. Part 370 describes the reporting requirements for providing the public with information on the hazardous chemicals in their communities. Part 372 sets forth the requirements for submission of information relating to the use and release of toxic chemicals. The specific toxic chemical listings in Subpart $D, \$ 372.65$, include the following chemical ingredients for organic polymer subsurface barriers:

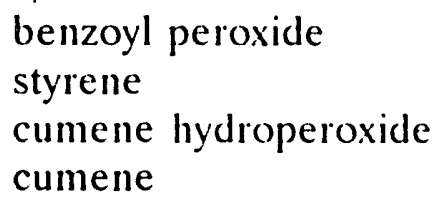

The threshold reporting quancity for any of these chemicals not manufactured or processed for distribution but otherwise used at a facility is 10,000 pounds per calendar year.

A related regulation under CERCLA rather than under Title III of SARA is promulgated in 40 CFR Part 302. This regulation designates hazardous substances and identifies reportable quantities for the release of each substance. This regulation also stipulates notification requirements for releases of these substances from a vessel or facility. The list of hazardous substances and reportable quantities in $\$ 302.4$ includes the following ingredients for organic polymer subsurface barriers:

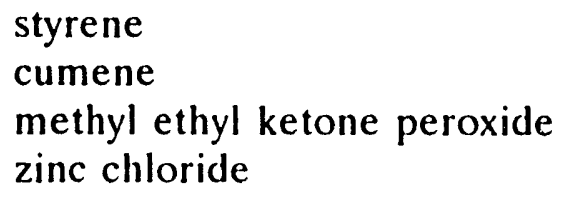




\subsection{Summary of Health, Safety, and Environmental Issues}

- Most of the chemical ingredients for non-traditional organic polymer barrier materials are regulated under 29 CFR $\$ 1910.1000$, Air Contaılıinants. We anticipate that standard industrial safety practices will keep exposure of the employees involved in the installation of subsurface barriers to the regulated air contaminants within the prescribed limits. These safety practices may involve administrative or engincering controls -. the preferable first choice alternative -- and/or, if such controls cannot achieve full compliance or are not feasible, the use of protective equipment by the employees.

- In 10 CFR Part 60, EPA presents the New Source Performance Standards (NSPS) under the Clean Air Act. The NSPS regulations set minimum Federal air emission regulations for a variety of industrial categories, some of which, if broadly defined, could encompass grouting or subsurface barrier installation operations utilizing organic polymers. Furthermore, EPA could at some point in the future add such operations to its list of industrial categories. In any case, emissions of several of the ingredients for organic polymer barrier materials are regulated here, especially in Subpart VV - Standards of Performance for Equipment Leaks of Volatile Organic Compounds (VOC) in the Synthetic Organic Chemicals Industry (seven compounds) but also in Subpart DDD - Standards of Performance for VOC Emissions from the Polymer Manufacturing Industry (one compound - styrene).

- Revisions of the Clean Air Act (CAA) have increased the list of designated hazardous air pollutants from eight to 189 and provided for future additions to the list. The amended CAA specifically includes cumene, N,N-dimethylaniline, and styrene: Federal Register notices have considered cumene hydroperoxide, triethanolamine, and $\mid \mathrm{p}$-|toluenesulfonic acid in rules relating to the National Emission Standards for Hazardous Air Pollutants. Although the CAA lists specific hazardous air pollutants, it has shifted the regulation of hazardous air pollutants from health-based, substance-specific standards to technology-based standards applicable to categories of industrial sources. Under the amended CAA, a major source is one which has the potential to emit with emissions controls at least 10 TPY of any single hazardous air pollutant or at least 25 TPY of any combination of them. The EPA Administrator is authorized to set lesser quantities for a major source.

- The Clean Water Act requires the EPA to establish technology-based effluent limitations on the quantities of specific pollutants which may be discharged by industrial facilities. These facilities must operate under a permit to discharge these pollutants. The CWA regulations list several of the chemical ingredients for organic polymer barrier materials: 
40 CFR $\$ 116.4$ includes styrene, zinc chloride, and methyl ethyl ketone peroxide in the list of designated hazardous substances and 40 CFR $\$ 117.3$ provides the reportable quantities for these substances;

40 CFR Part 414 specifies the effluent guidelines and standards -- including those for five organic polymer barrier ingredients ([N,N-jdimethylaniline, styrene, cumene hydroperoxide, cumene, and zinc chloride) -- for point sources in the organic chemicals, plastics, and synthetic fibers industries, the definitions of which could conceivably encompass installation of organic polymer barriers.

- The Safe Drinking Water Act requires drinking water from public water supply systems -- the definition of which will apply to many DOE facility water systems -to meet certain water quality standards at the tap. Two organic polymer barrier ingredients, styrene and zinc chloride, are mentioned in connection with the primary (Parts 141 and 142) and secondary (Part 143) drinking water regulations, respectively, and both are listed in the Drinking Water Regulations and Health advisories published by the EPA. Turbidity and microbiological limits in Part 141 could be of concern during the barrier installation process for both traditional and organic polymer barrier materials.

- The Safe Drinking Water Act also addresses underground injection control (UIC); 40 CFR Part 144 specifies the permitting and other program requirements for UIC programs and Part 146 sets technical criteria and standards. UIC programs are relevant to subsurface barrier installation because the barrier installation process falls within the definition of well injection as given in Part 144. Furthermore, Part 144 prohibits well injection which could result in contamination of underground sources of drinking water in violation of the primary drinking water regulations of Part 142. Note that these regulations apply to both traditional and organic polymer barrier materials.

- In response to the Bhopal disaster, the Emergency Planning and Community Rightto-Know Act addresses concerns regarding the storage and handling of toxic chemicals. Part 372 delineates the requirements for submission of information relating to the use and release of toxic chemicals and lists in Subpart D these toxic chemicals. The list in $\$ 372.65$ includes the following ingredients for organic polymer barrier materials: benzoyl peroxide, styrene, cumene hydroperoxide, and cumene. A related regulation under CERCLA in 40 CFR Part 302 designates hazardous substances and reportable quantities for release of these substances; the list in $\$ 302.4$ includes the following ingredients for organic polymer barrier materials: styrene, cumene, methyl ethyl ketone peroxide, and zinc chloride. 


\section{CONCLUSIONS AND RECOMMENDATIONS}

\subsection{Conclusions and Recommendations Regarding EPA's Acceptance of Subsurface Barrier Technology}

Since EPA guidance documents describe several kinds of subsurface barriers for controlling the movement of groundwater and/or contaminants at inactive waste disposal sites, we conclude that EPA considers this suite of technologies to constitute acceptable means of achieving such control. The selection of a technology or combination of technologies for any given site needing remediation must be conducted by means of the Superfund Process, with special emphasis on the remedial investigation and feasibility study portions. Of particular importance is the chemical compatibility of the barrier material with the wastes, leachates, and geohydrology of the remediation site. EPA emphasizes this compatibility by requiring thorough chemical and physical characterization of the barrier material, waste, leachate, and site geochemistry as well as compatibility testing of the barrier material with the likely remediation site environment. Futhermore, EPA requires that the potential release of toxic barrier material constituents be addressed as part of the characterization and testing.

We note that this level of characterization and testing is required of any technology under consideration for remediation of a particular site. For example, use of the more traditional barrier materials will not eliminate the need for characterization and testing; as mentioned earlier (in Section 2.1), the EPA literature describes the detrimental effects of certain chemicals on bentonite-based slurry walls and concludes that characterization and compatibility testing are required. We therefore recommend that such testing be carried out on any candidate barrier materials.

As a result of a preliminary series of telephone calls to EPA regarding EPA's acceptance of subsurface barriers constructed from polymer materials, we found that EPA's Technology Innovation Office saw no regulatory problem with the use of polymer materials for subsurface barriers as long as the final product is inert; EPA would have no further regulatory interest in what is essentially a construction operation."

\subsection{Conclusions and Recommendations Regarding Health, Safety, and Environmental Issues}

Based on discussions with representatives of the vendors of the polymer grouting materials, we note that the use of these materials in the construction industry has been accomplished with full compliance with the applicable health, safety, and environmental

\footnotetext{
"Telephone conversation between B. Siskind, BNL, and R. Steimle, Federal Technology Users' Group, Technology Innovation Office, EPA, on February 10, 1993.
} 
regulations. Therefore, we anticipate that such compliance is achievable when using these materials as subsurface barriers, the installation of which is essentially a construction operation. With the possible exception of the SDWA, the regulatory environment should be the same as that for utilizing these materials in building a road or in installing subsurface barriers for diverting groundwater around building foundation construction activities. We emphasize that there have been no regulatory roadblocks to such uses of these materials. Applicability of the SDWA to use of these materials in DOE site remediation will need to be determined on a site-specific basis, but as we noted in our discussion of the SDWA regulations earlier in this report if a site-specific analysis shows that direct application of a drinking water standard for groundwater protection is not justified based on anticipated risk to the public, then DOE may request an exemption, variance, or alternative concentration limit. We expect that for most, if not all cases, an assessment will result in a finding of no significant impact under the SDWA.

In order to achieve regulatory compliance for installation of subsurface barriers constructed from non-traditional materials, it is useful to be aware of what regulatory issues need to be addressed if only to be dismissed as not relevant or dealt with by routine permitting or control procedures. As we have seen in this report, the chemical ingredients for the non-traditional organic polymer barrier materials are regulated under a variety of health, safety, and environmental regulations. Most of them are regulated under 29 CFR $\$ 1910.100$ as air contaminants of concern for occupational safety and health. Several of them have the potential for being subject to one or both of two sets of regulations promulgated under the Clean Air Act, namely, minimum Federal air emissions regulations for a variety of industrial categories (the New Source Performance Standards -- NSPSs) and technology-based standards for hazardous air pollutants from certain industrial categories (the National Emission Standards for Hazardous Air Pollutants -- NESHAPs). Furthermore, several of these ingredients are subject to effluent limitations under the Clean Water Act and water quality standards under the Safe Drinking Water Act. In addition, several of the ingredients are subject to information requirements regarding their use release under the Emergency Planning and Community Right-to-Know Act and the Comprehensive Emergency Response, Compensation and Liability Act. Finally, the barrier installation process itself -- apart from chemical ingredients used in the process -- may be subject to the permitting, monitoring, and technical requirements placed on underground injection control programs by regulations promulgated under the Safe Drinking Water Act. Once again, we emphasize that permits and exemptions should be available, since these materials are commonly used in the commercial sector, often in similar applications, with full regulatory compliance.

We emphasize that while the chemical ingredients for the non-traditional barrier materials are subject to these regulations, the installation of barriers using these materials may be exempt from at least some of the environmental regulations. There are a variety of grounds for exemptions from the environmental regulations. 
For example, the NSPSs set emission limitations on classes of facilities at levels reflecting the best demonstrated control technology for that category of sources. It is not clear that installation of subsurface barriers falls into any of the existing industrial source categories. In addition, the NSPS must consider the cost of emissions reductions. Also, the barrier installation process for any given remediation site occurs once over a relatively short time span as opposed to most industrial activities, which are intended to continue for years or decades, e.g., a chemical production plant. Furthermore, it is not clear that the total quantities of the regulated ingredients at any given remediation site will exceed (or even approach) levels subject to regulation. For these reasons, we believe it will be possible to justify exemption of subsurface barrier installations from the NSPS. Similar arguments could be made to justify exemption from the NESHAPs, the Clean Water Act effluent limitations, and the information requirements. (For example, is there any realistic possibility that the emissions of hazardous air pollutants could even approach the 10 TPY limits under NESHAPs or the 10,000 pounds per calendar year under the community right-to-know regulations?). While these exemptions could be justified on a generic level for barrier installation operations if typical quantities of materials and emissions from unit operations are known, generic exemption from the water quality standards and from underground injection control regulations is not likely and will have to addressed on a site-specific and barrier-specific basis; once again, note that barriers constructed from traditional materials are subject to these regulations as well. Also, as we have already noted, the characterization and testing required for the non-traditional materials is also required for the more traditional portland-cement- and bentonite-based materials. We recommend that generic assessments of the air and water quality impacts of barrier installations, especially those involving the non-traditional materials, be conducted where possible.

Regarding the air contamination limitations under occupational safety and health regulations, we note that installation of barriers using the traditional bentonite- or portlandcement-based materials will require controls or protective measures regarding air contamination, at least with regard to airborne dust and particulates. In any case, we do not see compliance with these regulations to be an unduly onerous burden since compliance will likely involve standard industrial safety practices. 


\section{APPENDIX A - Barrier Placement Technologies}

\section{Slurry Walls}

To construct a slurry wall, a vertical trench is excavated and the trench filled with a suspension grout slurry to form an engineered panel. The most common slurries are water/ soil/bentonite and Portland cement/bentonite. Typically a bentonite slurry is used to hydraulically shore up the trench during construction and also seal the pores in the trench walls. Overlapping is insured by cutting into adjacent panels so the wall is "keyed" Slurry walls are generally 20 to 80 feet deep and 2 to 3 feet wide. Advantages of slurry walls include; the formation of continuous unbroken barriers, cost effective for massive structures, proven successful technology, can be used to $\sim 400$ feet depth, and develop minimal stresses. The disadvantages include; low chemical resistance, large amount of excavated soils which if contaminated must be treated and must be $2-3$ feet thick.

\section{Jet Grouting}

Jet grout curtains are constructed by injecting the grout through tubes into the strata to be waterproofed (Figure 4). The tubes are rotated while injecting at high pressures and slowly withdrawn from the ground. The high velocity jet masticates and mixes the soil and grouting material and results in a column resembling a pancake stack. After the grout pumped into the primary holes has gelled, grout is injected into secondary holes to fill gaps in the primary grout injection. Despite the grouting via the secondary holes, there are often problems in forming a continuous grout barrier, so that the overall low permeability is compromised. Grout curtains are more costly than slurry walls and generally cannot attain permeabilities as low. Grout curtains require more monitoring than other barriers because of the likelihood of gaps, which can enlarge quite rapidly if their is a sufficient hydraulic gradient across the curtain. Jet grouting is a very versatile technology that can utilize any pumpable grout and can be used in confined access areas such as under existing utilities surrounding underground storage tanks. Curtains can also be repaired if damaged or incomplete by additional grouting. Jet grouting can also be used in combination with other technologies such as sheet pilings where it has been used to seal the joints between panels.

\section{Deep Soil Auger Mixing}

Several large augers are used to bore into the soil followed by introduction of a grouting material. The augers mix the soil and grout and are gradually retrieved from the ground. The resultant panel generally has more favorable properties (e.g. permeability) compared to jet grouted curtains, have fewer breaks and more consistent dimensions. Deep soil mixing is a proven technology but is limited to $\sim 100$ feet depth and results in a much larger quantity of spoils when compared to jet grouting. 


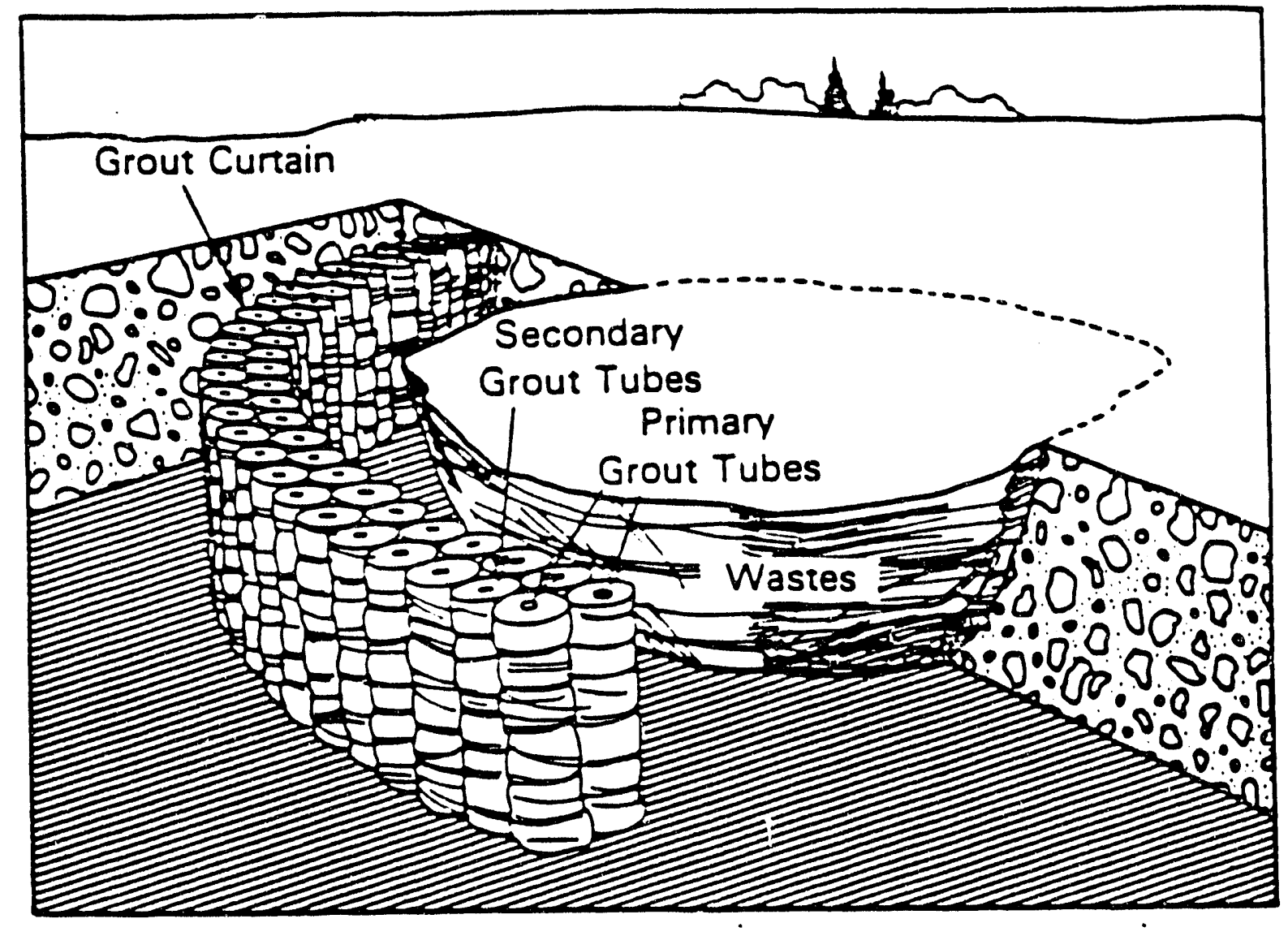

Figure 4. Schematic of Grout Curtain Around Waste Site' 


\section{Permeation Grouting}

A grouting material of low viscosity (typically $<300 \mathrm{cps}$ ) is injected into the ground through a series of injection wells. The grout penetrates the soil where it then sets forming the barrier in-situ. The barrier is made continuous by overlapping the injection zones. Permeation is advantageous in having little spoils, producing low stresses, and can produce low permeable barriers when used in conjunction with advanced polymer systems. Permeation grouting is the principle method of employing acrylates such as AC-400 for construction industries. Disadvantages include cost and the technology is unproven for use with advanced polymer systems.

\section{Vibrating Beam Cutoff Walls}

This method consists of vibrating a specially designed beam into the ground. The barrier material is tremmied into the ground through the beam as the beam is slowly extracted from the ground. A continuous wall is created by repeating the process adjacent to the just formed panel. This technique has been used in conventional construction but has not been proven for remedial applications. Vibrating beam produced barriers can produce low permeability walls, in tight spaces and with little or no spoils. Disadvantages include; uncertainty in the alignment of beams may produce a barrier with gaps, the barriers are thin, typically $6-8$ inches, and is limited to soils that can be penetrated by vibrating beam.

\section{Sheet Piling}

Sheet piling is another method of forming a groundwater barrier. Sheet piles can be made of wood, pre-cast concrete, plastic or steel. Wood tends to be an ineffective barrier and concrete is used primarily where great strength is required. The barrier materials are generally installed by driving the sheets into the ground around the waste site. The seams are sealed using a grout. Sealing of joints between sheets is often questionable and cannot normally be verified. Steel pilings are generally used only for temporary dewatering for other construction or as erosion protection for slurry walls. Corrosion of the steel by the soil limits the performance life of a sheet piling wall to between 7 and 40 years. ${ }^{1}$ Plastic (e.g. high density polyethylene) sheet is a relatively new application and has had only limited actual field use. The integrity of the joints has not been proven but some methods might allow monitoring sensors to be placed in the seams. This appears to be a promising technology for vertical (or near vertical) barriers. 


\section{Other technologies}

There are other methods for placing a subsurface barrier which are either seldom used or recently developed for remedial operations. Diaphragm walls are precast panel, typically reinforced concrete but could be polymer concrete, that are placed by slurry trench techniques. With proper attention to joint construction diaphragm walls can produce a quality vertical barrier. Cost is cited as the reason diaphragm walls are seldom used.

Rock grouting may be used for sealing fractures, fissures, solution cavities, or other voids in rock. The authors of the EPA's Remedial Action Handbook' could find no applications of this technique in the literature but consider it "One of the greatest potential uses for grouting in hazardous waste site remediation..." 


\section{REFERENCES}

1. Science Applications International Corporation, "HANDBOOK: Remedial Action at Waste Disposal Sites (Revised)," EPA/625/6-85/006, October 1985.

2. "Environmental Guidance Program Reference Book - Comprehensive Environmental Response, Compensation, and Liability Act," ORNL/M-1572, Revision 11, October 1, 1991.

3. U.S. Environmental Protection Agency, "Engineering Bulletin - Slurry Walls," EPA/540/S-92/008, October 1992.

4. P. A. Spooner et al., "Slurry Trench Construction for Pollution Migration Control," EPA-540/2-84-001, February 1984.

5. R. H. Karol, "Chemical Grouting," 1990. Marcel Dekker. New York

6. Franz, E.M., Heiser, J.H., and Colombo, P., Immobilization of Sodium Nitrate Waste with Polymers, Topical Report, Brookhaven National Laboratory, April 1990, BNL52081.

7. Dow Chemical Company, The Dow System for Solidification of Low-Level Radioactive Waste From Nuclear Power Plants, Topical Report, DNS-RSS-001-NP-A, The Dow Chemical Company, Midland, Michigan, March 1978.

8. Williamson, A.S., and A. Husian, "A Plant for Immobilizing Low-Level Aqueous Waste in Water-Extendible Polymer," International Topical Meeting, Niagara Falls, NY, September 1986.

9. Vipulanandan, C., and Krishnan, S., "Solidification/Stabilization of Phenolic Waste with Cementitious and Polymeric Materials", 2nd Annual Symposium on Solidification/Stabilization - Mechanisms \& Applications, Gulf Coast Hazardous Substance Research Center, Beaumont, Texas, February 15-16, 1990.

10. Neilson, R.M., and Colombo, P., Waste Form Development Program, Annual Progress Report, September 1982, BNL-51614, Brookhaven National Laboratory, Upton, New York.

11. Form No. 296-320-1290X SMG, Chemical Resistance and Engineering Guide, Derakane Resins, Dow Plastics, The Dow Chemical Company, Midland, Michigan.

12. Bodocsi, A. and Bowers, M.T., "Permeability of Acrylate, Urethane, and Silicate Grouted Sands with Chemicals", Journal of Geotechnical Engineering, Vol. 117, No. 8, Aug 1991, pp 1227-1244. 
13. Karol, R. K., Chemical Grouting, Second edition, Marcel Dekker, Inc., N.Y.,1990.

14. McBee, W.C., and Sullivan. T.A., Development of Specialized Sulfur Concretes, U.S. Department of the Interior, Bureau of Mines, 1979.

15. "Environmental Guidance Program Reference Book -Clean Air Act," ORNL/M1408. Revision 4. Algust 1, 1991.

16. "Environmental Guidance Program Reference Book - Clean Water Act (Excluding Section 404)," ORNL/M-1278, Ruvision 5, October 1, 1990.

17. "Environmental Guidance Progıam Reference Book - Safe Drinking Water sict." ORNL/M-1899, Revision 6, September 15, 1992. 

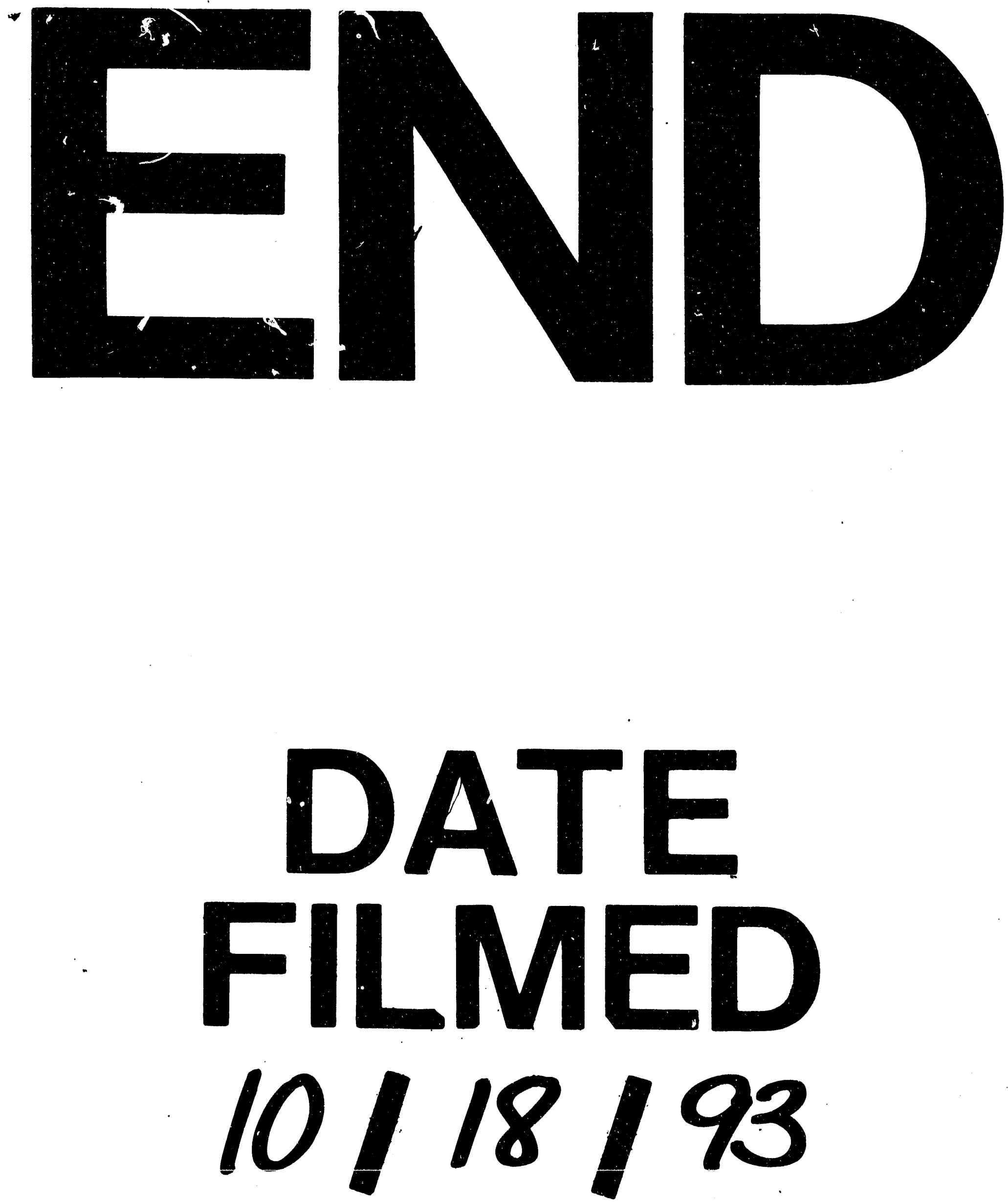
